Int. J. Dev. Biol. 53: 631-639 (2009)

doi: $10.1387 / \mathrm{ijdb} .082823 \mathrm{kh}$

\title{
The Xenopus Bowline/Ripply family proteins negatively regulate the transcriptional activity of T-box transcription factors
}

\author{
KEISUKE HITACHI ${ }^{1, \#}$, HIROKI DANNO ${ }^{1}$, SHUNSUKE TAZUMI ${ }^{2}$, YUKO AIHARA ${ }^{2}$, HIDEHO UCHIYAMA ${ }^{2}$, \\ KOJI OKABAYASHI ${ }^{3}$, AKIKO KONDOW ${ }^{1, \# \#}$ and MAKOTO ASASHIMA*,1,3,4
}

\begin{abstract}
${ }^{1}$ Department of Life Sciences (Biology), Graduate School of Arts and Sciences, The University of Tokyo, Meguro-ku, Tokyo, ${ }^{2}$ International Graduate School of Arts and Sciences, Yokohama City University, Kanazawa-ku, Yokohama, ${ }^{3}$ ICORP Organ Regeneration Project, Japan Science and Technology Agency (JST), Meguro-ku, Tokyo and ${ }^{4}$ Organ Development Research Laboratory, National Institute of Advanced Industrial Science and Technology (AIST), Tsukuba Central 4, Tsukuba, Ibaraki, Japan
\end{abstract}

\begin{abstract}
Bowline, which is a member of the Xenopus Bowline/Ripply family of proteins, represses the transcription of somitogenesis-related genes before somite segmentation, which makes Bowline indispensable for somitogenesis. Although there are three bowline/Ripply family genes in each vertebrate species, it is not known whether the Bowline/Ripply family proteins share a common role in development. To elucidate their developmental roles, we examined the expression patterns and functions of the Xenopus Bowline/Ripply family proteins Bowline, Ledgerline, and a novel member of this protein family, xRipply3. We found that the expression patterns of bowline and ledgerline overlapped in the presomitic mesoderm (PSM), whereas ledgerline was additionally expressed in the newly formed somites. In addition, we isolated $x R i p p l y 3$, which is expressed in the pharyngeal region. Co-immunoprecipitation assays revealed that Ledgerline and xRipply3 interacted with T-box proteins and the transcriptional co-repressor Groucho/TLE. In luciferase assays, xRipply3 weakly suppressed the transcriptional activity of Tbx1, while Ledgerline strongly suppressed that of Tbx6. In line with the repressive role of Ledgerline, knockdown of Ledgerline resulted in enlargement of expression regions of the somitogenesis-related-genes mespb and Tbx6. Inhibition of histone deacetylase activity increased the expression of mespb, as seen in the Bowline and Ledgerline knockdown experiments. These results suggest that the Groucho-HDAC complex is required for the repressive activity of Bowline/Ripply family proteins during Xenopus somitogenesis. We conclude that although the Xenopus Bowline/Ripply family proteins Bowline, Ledgerline and xRipply3 are expressed differentially, they all act as negative regulators of T-box proteins.
\end{abstract}

KEY WORDS: somitogenesis, ripply, presomitic mesoderm, Tbx6, groucho

\section{Introduction}

The T-box family genes, which encode transcription factors that contain the T-box DNA binding domain, are highly conserved in metazoans. T-box transcription factors play critical roles in the organogenesis of, for example, the heart, pituitary gland, and limbs. Thus, various developmental defects have been linked to mutations in T-box genes in humans (Naiche et al., 2005). Tbx6, which is a member of the T-box family of transcription factors, functions as a transcriptional activator and is involved in the specification of the posterior paraxial mesoderm and the formation of the somite, which sequentially buds off from the paraxial, presomitic mesoderm (PSM). Mouse embryos with a null muta-

Abbreviations used in this paper: HDAC, histone deacetylase; PSM, presomitic mesoderm; Tbx, T-box; TLE, transducin-like Enhancer-of-split.

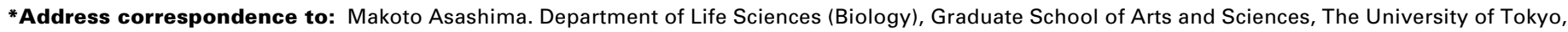
3-8-1 Komaba, Meguro-ku, Tokyo 153-8902, Japan. Fax: +81-3-5454-4330. e-mail: asashi@bio.c.u-tokyo.ac.jp

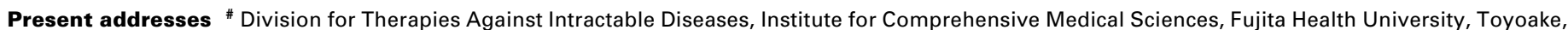

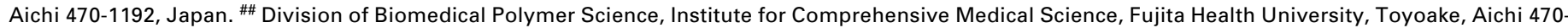
1192, Japan 
tion in Tbx6 are embryonically lethal at mid-gestation due to a deficiency of caudal somites (Chapman and Papaioannou, 1998). Moreover, mice that carry a hypomorphic allele of Tbx6 show disruption of the anteroposterior polarity of their somites (Beckers et al., 2000; Nacke et al., 2000; Theiler and Varnum, 1985; Watabe-Rudolph et al., 2002; White et al., 2003). These findings underline the requirement of Tbx6 for somite formation.

We and others previously identified a novel protein family, Bowline/Ripply, from the mouse, African clawed frog (Xenopus laevis), zebrafish, and amphioxus (Chan et al., 2007; Chan et al., 2006; Kawamura et al., 2005; Kondow et al., 2006; Li et al., 2006; Morimoto et al., 2007). In vertebrates, two bowline/Ripply family genes have been identified and characterized to date. The expression region of bowline, which is a member of the bowline/ Ripply family gene in Xenopus, is restricted to the anterior PSM during somitogenesis (Kondow et al., 2006). In bowline-knockdown embryos, somite boundary formation is disrupted, and the regions of mespb and $X$-delta-2 expression, which are restricted to the anterior PSM during normal development, are expanded anteriorly (Kondow et al., 2007). The corresponding defects in somites were observed in Ripply1-deficient embryos of zebrafish and in Ripply2-knockout mice (Chan et al., 2007; Kawamura et al., 2005; Morimoto et al., 2007). Thus, Bowline/Ripply family proteins are essential for the proper formation of somite boundaries in vertebrates. Bowline/Ripply family proteins have two conserved domains: the WRPW tetrapeptide motif and the Ripply homology domain/Bowline-DSCR-Ledgerline conserved region (Ripply/BDLC domain). Through the WRPW-tetrapeptide motif, Xenopus Bowline and zebrafish Ripply1 interact with the transcriptional co-repressor Groucho/TLE (Kawamura et al., 2005; Kondow et al., 2006). We have previously shown that Bowline interacts with Tbx6 protein via the Ripply/BDLC domain and suppresses the transcriptional activity of Tbx6 (Kondow et al., 2007). Similarly, in zebrafish, Ripply1 interacts with Tbx24, which is related to Tbx6, to suppress the transcriptional activity of Tbx24
(Kawamura et al., 2008).

Previously, we isolated an additional Xenopus bowline/Ripply family gene, ledgerline (Chan et al., 2006). Although ledgerline is also expressed in the anterior PSM during Xenopus somitogenesis, its molecular function in somitogenesis remains largely unknown. In the present report, we show that Ledgerline interacts with the Tbx6 protein and suppresses, to the same extent as Bowline, the transcriptional activity of Tbx6. Loss of function of ledgerline resulted in significant changes to the expression patterns of mespb and Tbx6.

We also show that a novel Xenopus bowline/Ripply family gene, $x$ Ripply3, is expressed in the pharyngeal region during Xenopus development. Furthermore, we demonstrate that xRipply3 interacts with the T-box protein Tbx1 and suppresses the transcriptional activity of Tbx1. Our findings reveal that Xenopus Bowline/Ripply family proteins share the common feature of acting as negative regulators of T-box proteins. In addition, our characterization of $x$ Ripply3 suggests the involvement of this novel Bowline/Ripply family protein in the development of the pharyngeal region.

\section{Results}

\section{Expression profiles of Xenopus bowline/Ripply genes in the presomitic mesoderm}

Ledgerline is one of the bowline/Ripply family genes in Xenopus and is expressed in the PSM (Chan et al., 2006). However, the definitive expression pattern of ledgerline in the PSM has not been clarified. To define the spatial expression pattern of ledgerline in the PSM, we compared the mRNA distribution patterns of ledgerline and bowline, which is another Xenopus bowline/Ripply family gene. Serial sections of Xenopus embryos at stage 20 were prepared, and the ledgerline and bowline transcripts were detected by in situ hybridization (Fig. 1A-B). The expression of bowline was observed in the anterior halves of the S-I, S-II, and
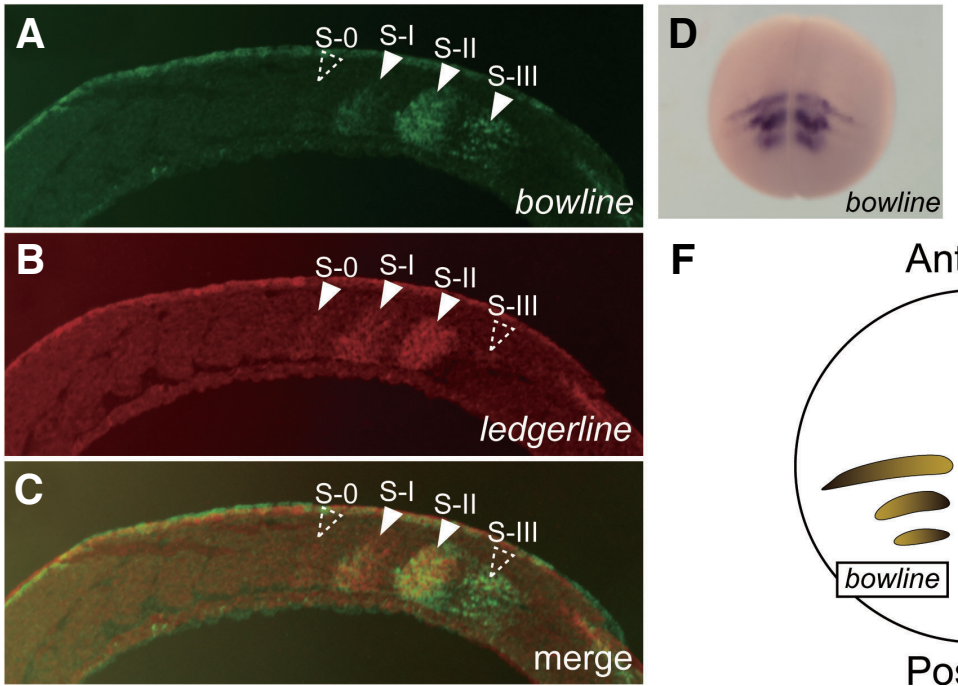

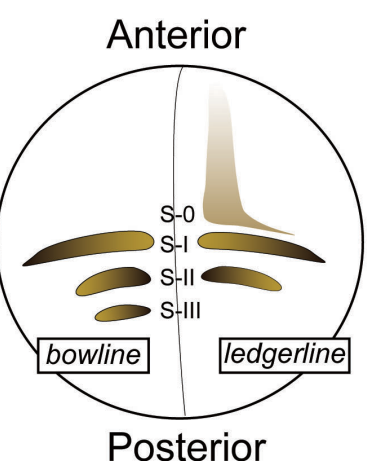

$\mathbf{F}$

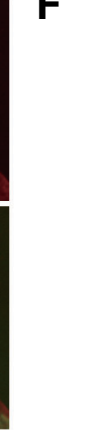

formed somites, as well as in the somitomeres. The black bar indicates ledgerline expression in the new

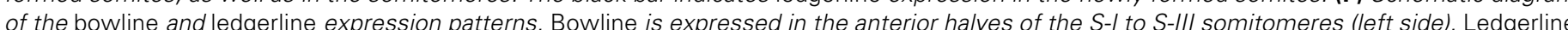

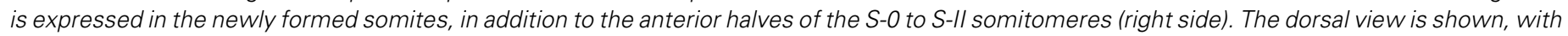
anterior being towards the top. The nomenclature used for the somitomeres follows that proposed earlier (Pourquie and Tam, 2001).

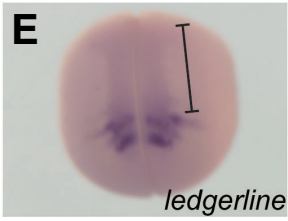

Fig. 1. Differential expression patterns of the bowline and ledgerline genes during Xenopus somitogenesis. (A,B) Expression patterns of bowline and ledgerline in the Xenopus PSM. Longitudinal serial sections of a stage 20 embryo were stained for bowline (A) and ledgerline (B), and the results are shown as a pseudocolor display. The white arrowheads in $(A)$ and $(B)$ represent the regions in which bowline and ledgerline, respectively, are expressed. (C) Merged image of $(A, B)$. The white arrowheads in (C) represent the regions in which the expression patterns of bowline and ledgerline overlap. The sections are orientated so that the anterior part is to the left. (D,E) Whole-mount in situ hybridization for bowline (D) and ledgerline (E). The expression of bowline is restricted to the somitomeres. Interestingly, ledgerline is expressed in the newly ly formed somites. (F) Schematic diagram 
Fig. 2. Tbx6 is required for bowline and ledgerline expression during Xenopus development. (A) The expression of bowline and ledgerline is induced by the synergistic effects of Tbx6, mespb, and E47. RT-PCR analysis shows that overexpression of the mixture of Tbx6, mespb, and E47 mRNA species induces ectopic bowline and ledgerline expression in gastrula-stage Xenopus embryos. ODC (ornithine decarboxylase) was used as an internal control. (B-E) Expression of bowline mRNA and ledgerline mRNA in Xtbx6 exint-MO-injected embryos. All the embryos were fixed at stage 19 for whole-mount in situ hybridization to detect the expression of bowline (B,C) and ledgerline (D,E). Magenta-Gal staining indicates the injected side. (B,D) A representative embryo injected with $50 \mathrm{ng}$ Xtbx6 exint-MO. Inhibition of the splicing of Tbx6 mRNA results in loss of expression of bowline and ledgerline. The white arrowheads in (B) and (D) indicate reduced bowline and ledgerline expression, respectively. (C,E) Representative embryos injected with 50 ng Xtbx6 exint-MO and 2 pg or 10 pg Xenopus Tbx6 mRNA, respectively. The white arrowheads in $(C, E)$ indicate rescued bowline and ledgerline expression, respectively.
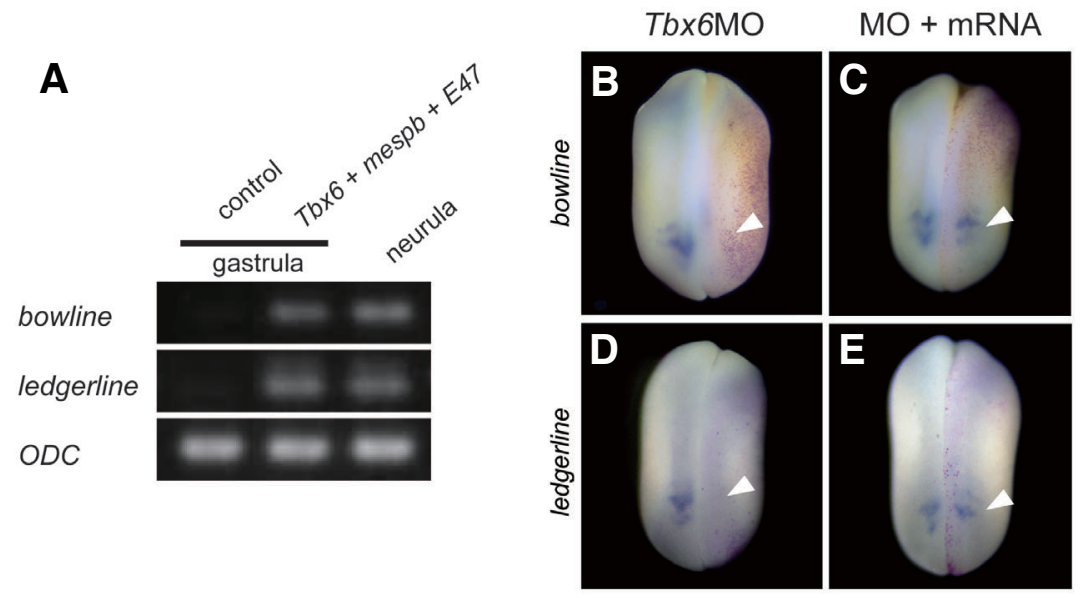

S-III somitomeres, as previously reported (Kondow et al., 2006), while the expression of ledgerline was observed in the anterior halves of the SO, S-I, and S-II somitomeres and the newly formed somites (Fig. 1A, B, D, E). The two gene transcripts co-localize in the anterior halves of the S-I and S-II somitomeres (indicated in yellow in the merged image; Fig. 1C). Thus, the spatial expression patterns of bowline and ledgerline are partially overlapped in the PSM, in which the ledgerline transcripts localize anteriorly with respect to the bowline transcripts (Fig. 1F).

\section{Tbx6 is indispensable for the expression of both bowline and ledgerline}

We have shown previously that the expression of bowline is activated by the combined effects of three transcriptional factors, Tbx6, mespb, and E47 (Hitachi et al., 2008b). We examined whether the expression of ledgerline is also regulated by these three factors. The in vitro-transcribed mRNA species of Tbx6, $m e s p b$, and $E 47$ were injected into 2-cell stage embryos of Xenopus, and the ledgerline transcripts were detected by RT-PCR at the gastrula stage, at which point endogenous ledgerline transcripts are not detected during normal development. Induced expression of ledgerline was detected (Fig. 2A). This suggests that ledgerline expression is also activated by the combination of Tbx6, mespb, and E47.

To elucidate further the requirement of Tbx6 for endogenous bowline and ledgerline expression, we used antisense morpholino oligonucleotides $(\mathrm{MO})$ to inhibit the function of Tbx6. The MO that targets the exon1/intron1 junction of Xenopus Tbx6 (Xtbx6 exintMO) specifically blocks Tbx6 function (Tazumi et al., 2008). The Xtbx6 exint-MO (50 ng) was injected into the ventral marginal zone and dorsal lateral marginal zone of embryos at the 4-cell stage, with the uninjected side serving as a control. These embryos were cultured until stage 19, and the spatial expression patterns of bowline and ledgerline were examined by whole-mount in situ hybridization. The expression of bowline and ledgerline was lost in the MO-injected side $(95 \%, n=38$; and $100 \%, n=41$, respectively) (Fig. 2B and D). The loss of bowline expression was rescued to a moderate extent by co-injection of Xtbx6 exint-MO with $\mathrm{Tbx} 6$ mRNA (19\%, n=37) (Fig. 2C). However, in the experiment looking at the rescue of ledgerline expression by co-injection of Xtbx6 exint-MO with Tbx6 mRNA, ledgerline expression was rescued at a rate of only $1 / 37$ (Fig. $2 \mathrm{E}$ ). It is possible that the mechanism responsible for ledgerline expression regulation is different from that for bowline expression. Nevertheless, these results indicate that Tbx6 is indispensable for the expression of both bowline and ledgerline during Xenopus somitogenesis.

\section{Bowline and Ledgerline suppress the transcriptional activity of Tbx6}

Previously, we showed that Bowline acts synergistically with Grg4, which is a Xenopus Groucho/TLE protein, to repress mespb promoter activity activated by the Tbx6VP16 protein, which is the constitutively active form of Tbx6 (Kondow et al., 2007). We examined whether Bowline suppresses the transcriptional activity of the wild-type Tbx6 protein. Transfection of wild-type Tbx6 together with Notch $\Delta E$, which is a constitutively active component of Notch signaling, activated the mespb promoter in cultured COS7 cells (Fig. 3A), and this activation was repressed by Bowline (Fig. $3 A)$. Thus, we confirmed that Bowline suppresses the transcriptional activity of wild-type Tbx6. Interestingly, Ledgerline, together with Grg4, repressed mespb promoter activity activated by Tbx6 and Notch $\Delta \mathrm{E}$, or by Tbx6VP16 alone (Fig. 3B and C). In addition, Ledgerline interacted with Grg4 and the Tbx6 protein, as shown in the co-immunoprecipitation assay (Fig. 3D and 3E). These results indicate that Ledgerline is a negative regulator of Tbx6, as is the Bowline protein.

To examine the molecular function of Ledgerline during Xenopus somitogenesis, we blocked the translational initiation of Ledgerline using an antisense $\mathrm{MO}$ against ledgerline. LedgerlineMO was unilaterally injected into 4-cell-stage embryos, and the spatial expression patterns of mespb and Tbx6 were examined by whole-mount in situ hybridization. In the embryos injected with Ledgerline-MO, the regions of mespb and Tbx6 expression were expanded anteriorly in comparison with the uninjected side $(65 \%$, $n=20$ and $93 \%, n=15$, respectively) (Fig. 4A-D), which indicates that Ledgerline represses the expression of both mespb and Tbx6 during Xenopus somitogenesis at the anterior PSM. Next, we investigated the involvement of Groucho/TLE protein in this repres- 

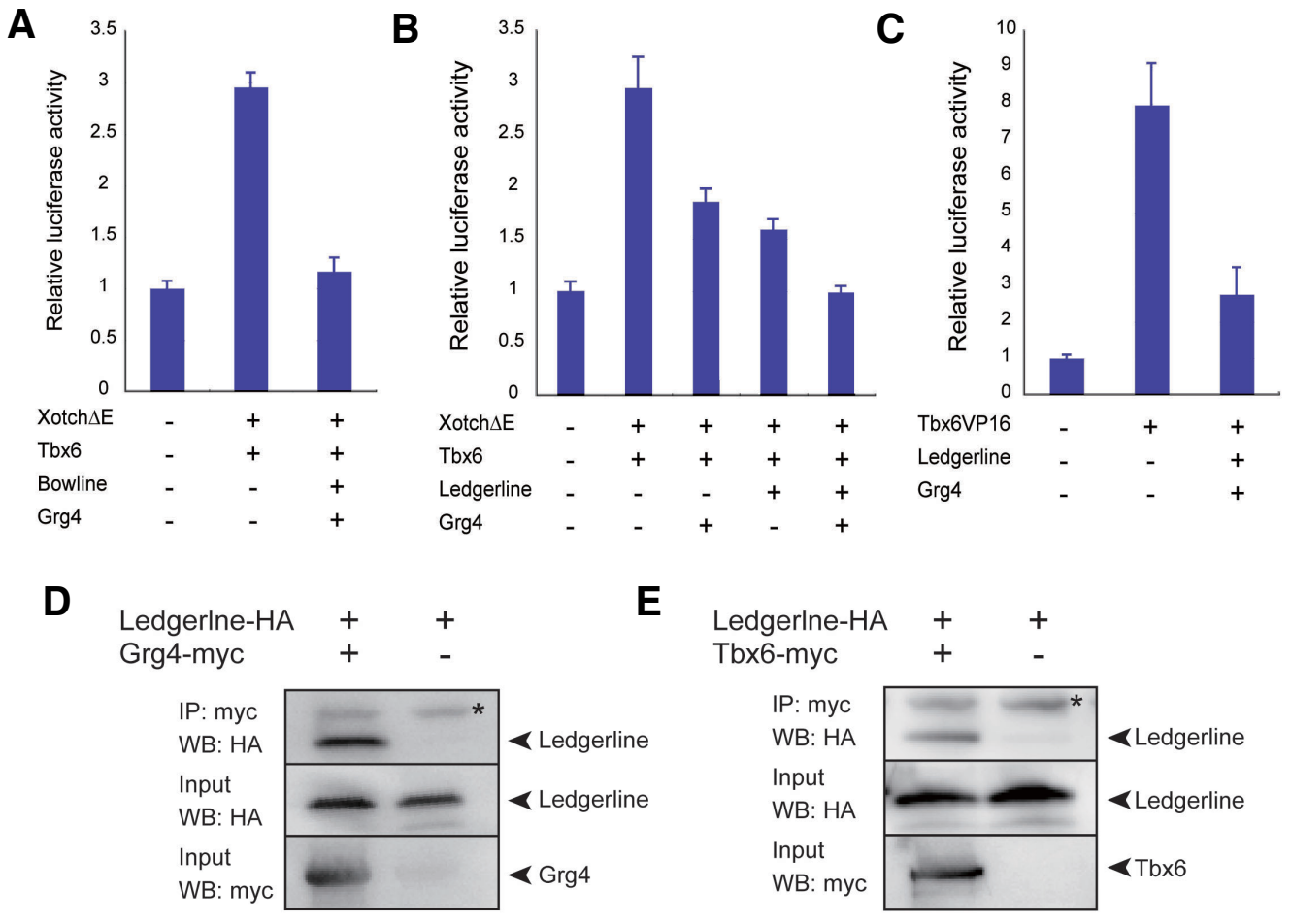

Fig. 3. Ledgerline suppresses the transcriptional activity of Tbx6. (AC) Luciferase assays of mespb promoter activity. (A) Bowline, in combination with Grg4, represses the activity of the mespb promoter activated by Tbx6 and Xotch $\triangle E$. COS7 cells were transfected with the pGL4.2Thy1 (20 ng) and a combination of the indicated expression vectors, i.e., Tbx6 and Xotch $\Delta E(150 \mathrm{ng}$ each) and Bowline and Grg4 (50 ng each). (B) Ledgerline also represses the activity of the mespb promoter activated by Tbx6 and Xotch $\Delta E$. COS7 cells were transfected with the pGL4.2Thy1 (20 ng) and a combination of the indicated expression vectors, i.e., Tbx6 and Xotch $\Delta E(150 \mathrm{ng}$ each) and Ledgerline and Grg4 (50 ng each). (C) Ledgerline, in combination with Grg4, represses the activity of the mespb promoter activated by Tbx6VP16. COS7 cells were transfected with pGL4.2Thy1 (20 ng) and a combination of the indicated expression vectors, i.e., Tbx6VP16 (200 ng) and Ledgerline and Grg4 (50 ng each). Error bars represent the SEM of three independent experiments. (D) Interaction between Ledgerline and Grg4 proteins in Xenopus embryos. Protein extracts of Xenopus embryos coinjected with HA-ledgerline mRNA and myc-Grg4 mRNA (500 pg each) were subjected to co-immunoprecipitation with the anti-myc antibody. (E) Interaction between Ledgerline and Tbx6 proteins in Xenopus embryos. Protein extracts of Xenopus embryos co-injected with HA-ledgerline mRNA and myc-Tbx6 mRNA (500 pg each) were subjected to immunoprecipitation with the anti-myc antibody. The asterisks indicate non-specific bands.

sive effect in vivo. The repressive activity of Groucho/TLE protein is mediated by histone deacetylase (HDAC). Thus, we used trichostatin A to block the repressive activity of HDAC during Xenopus somitogenesis. Trichostatin A treatment induced the anterior expansion of mespb expression, as seen for knockdown of Ledgerline $(100 \%$, $\mathrm{n}=8$ ) (Fig. 4E and F). This result suggests that the repressive activity of this Bowline/Ripply family protein is mediated by the Groucho/ TLE-HDAC complex during Xenopus somitogenesis.

\section{Isolation and characterization of a third Xenopus bowline/ Ripply gene, xRipply3}

The third bowline/Ripply gene, Ripply3, was found in the human, mouse, and zebrafish genomes. However, their expression patterns and molecular functions of these Ripply 3 genes have not been reported. We isolated the Xenopus Ripply3 gene, designated as $x$ Ripply3 (GenBank accession no. AB455086). This gene encodes 170 amino acids. The nucleotide sequences around the first in-frame methionine match the Kozak consensus sequence (Kozak, 1987) and most likely represent the translation initiation site.

Comparison of the amino acid sequences of the human, mouse, frog and zebrafish Ripply3 proteins revealed that the tetrapeptide WRPW, which acts as a Grouch/TLE recruitment motif, is completely conserved among these proteins (Fig. 5A). Moreover, the tetrapeptide FPVQ in the Ripply/BDLC region, which is essential for interactions with T-box proteins (Kawamura et al., 2008) was also completely conserved (Fig. 5A). Phylogenetic analysis showed that Ripply3 forms a subfamily among the Bowline/Ripply family proteins (Fig. 5B). We next examined the subcellular localization of the
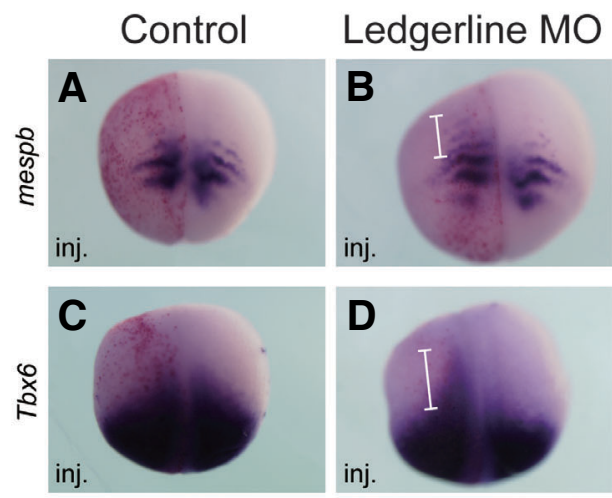

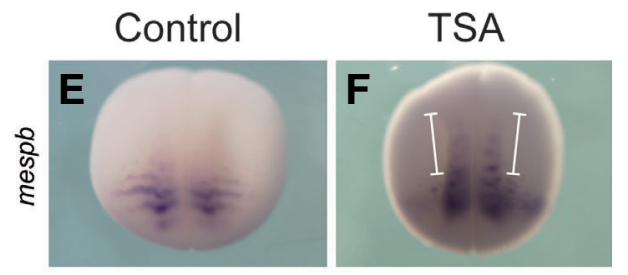

Fig. 4. Knockdown of Ledgerline causes abnormal expression of mespb and Tbx6 during Xenopus somitogenesis. (A-D) Whole-mount in situ hybridization for mespb (A,B) and Tbx6 (C,D). Embryos at the 4-cell stage were injected with Control-MO $(\mathbf{A}, \mathbf{C})$ or Ledgerline-MO (B,D). In the embryos injected with Ledgerline-MO, the regions of mespb and Tbx6 expression were expanded anteriorly (white bar in B and D, respectively). (E,F) Wholemount in situ hybridization for mespb. Embryos were treated with 500 nM trichostatin A (TSA) or DMSO for $4 \mathrm{~h}$. Anteriorly expanded mespb expression was induced by TSA (white bars in

F). Dorsal views are shown with the anterior towards the top. 
A

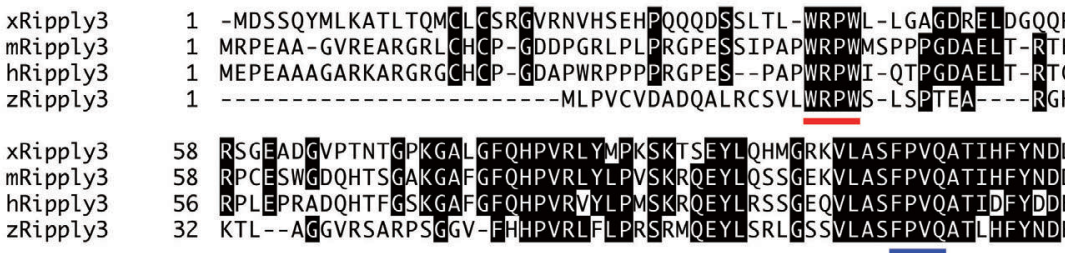

xRipply3 mRipply3 hRipply3 zRipply3

xRipply3 mRipply3 hRipply3 zRipply3

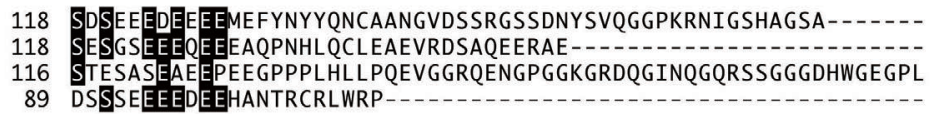

89 DSSSEEEEDEEHANTRCRLWRP_-

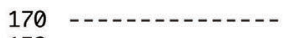

152

176 PQGVSSRGGKCSSSK

110
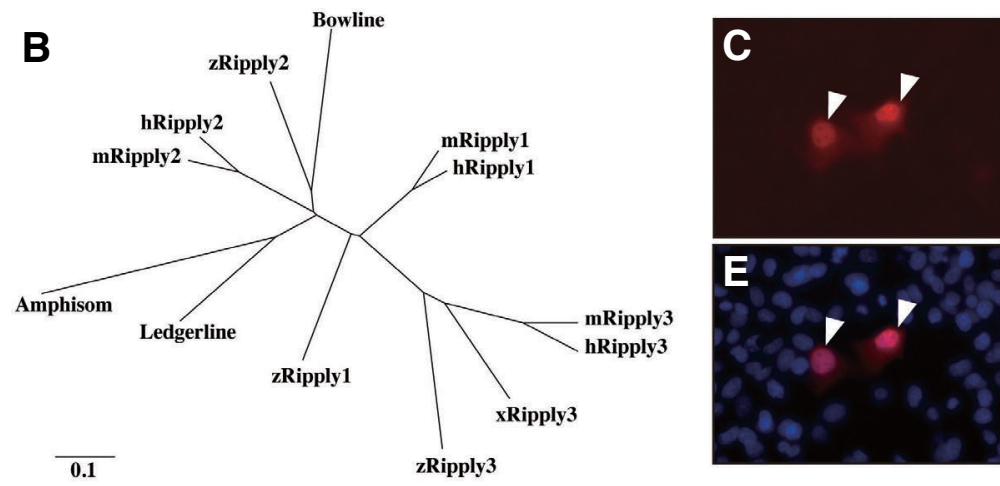

Fig. 5. Structure and subcellular localization of xRipply3. (A) Comparison of the Ripply3 protein sequences in human, mouse, frog, and zebrafish. Identical amino acids are indicated by a black background. Conserved WRPW and FPVQ motifs are shown in red and blue underlines, respectively. (B) Phylogenetic tree of the Bowline/Ripply family proteins in human, mouse, frog, zebrafish, and amphioxus. (C-E) Subcellular localization of the xRipply3-HA protein in COS7 cells. Cultured cells were transfected with the HA-tagged xRipply3 plasmid and visualized by immunohistochemical staining with the anti-HA antibody. The localization of XRipply3-HA is mainly nuclear. Nuclei are counterstained with DAPI.

xRipply3 protein. HA-tagged xRipply3 was transfected into COS7 cells, and the HA-xRipply3 protein was localized by immunocytochemistry with an anti-HA antibody. In these COS7 cells, HA$x$ Ripply3 was mainly localized to the nucleus (Fig. 5C-E). These results suggest that $x$ Ripply 3 functions as a transcriptional modulator in the nucleus, as do other Bowline/Ripply family proteins.

Whole-mount in situhybridization for $x$ Ripply3showed that $x$ Ripply 3 was expressed in the region close to the heart mesoderm at the neurula stage (Fig. 6A). At the tailbud stage, $x$ Ripply3was expressed in the pharyngeal region (Fig. $6 \mathrm{~B}$ and $\mathrm{C}$ ). Microscopic observations of sections of the Xenopus embryos hybridized with the $x$ Ripply 3 antisense probe confirmed that the expression of $x$ Ripply 3 was restricted to the pharyngeal region during Xenopus development (Fig. 6D). Similarly, the expression of murine Ripply3 was also observed primarily in the pharyngeal region (Fig. $6 \mathrm{E}$ and F). These results indicate that Ripply 3 is expressed in the pharyngeal region, and reveal that the expression profiles of the Xenopus and murine Ripply3 genes differ from those of already known bowline/Ripply family genes.

\section{xRipply3 suppresses the transcriptional activity of Tbx1}

Two of the Bowline/Ripply family proteins, Bowline and Ledgerline, suppressed the transcriptional activity of Tbx6. Therefore, we hy-

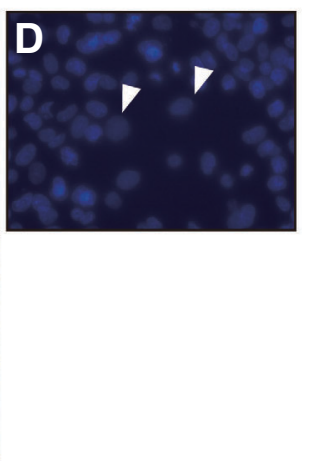

pothesized that xRipply3 also suppresses the transcriptional activities of T-box proteins in the pharyngeal region. We examined whether xRipply3 suppresses the transcriptional activity of Tbx1, since Tbx1 is an activator-type $\mathrm{T}$-box protein and plays a central role in the development of the pharyngeal apparatus (Baldini, 2005; Zoupa et al., 2006). A reporter construct that carries tandem Tbx1 binding sites upstream of luciferase ( $p$ GL4-Tbox, Fig. 7A) was created, and assayed for luciferase activity in the absence or presence of Tbx1. Transfection of Xenopus Tbx 1 increased the luciferase activity of pGL4-Tbox 15- to 45-fold compared to that of the control (Fig. 7B). As expected, transfection of $x$ Ripply 3 decreased in a dose-dependentmanner the luciferase activity of pGL4Tbox activated by Tbx1 (Fig. 7C). These results suggest that $x$ Ripply 3 functions as a negative regulator of Tbx1.

Previously, we showed that the repressive activity of Bowline is mediated by interaction with the Tbx6 and Groucho/TLE proteins (Kondow et al., 2007). Therefore, we examined whether $x$ Ripply3 interacts with the Tbx1 and Groucho/TLE proteins in co-immunoprecipitation assays. In the presence of myc-tagged Tbx1, HA-tagged xRipply3 was immunoprecipitated by the anti-myc antibody (Fig. 7D). Similarly, the interaction between HA-tagged xRipply3 and myc-tagged Grg4 was revealed in a co-immunoprecipitation assay (Fig. 7E). These results suggest that the suppressive activity of xRipply3 is mediated by interactions with the Tbx1 and Groucho/TLE proteins.

Finally, to elucidate the relationship between $x$ Ripply3 and Tbx1 in vivo, we compared the expression patterns of $x$ Ripply3, Tbx1, and Fgf8, which is a downstream gene of $T b x 1$, in the Xenopus pharyngeal apparatus. Examinations of frontal sections showed that the $x$ Ripply3- and Fgf8-expressing region differed from the Tbx1-expressing region (Fig. $7 \mathrm{~F}-\mathrm{H}$ ). It is reported that $T b \times 1$ is expressed in the pharyngeal arch region in $X$. tropicalis (Showell et al., 2006). Thus, the xRipply3-and Fgf8-expressing regions are likely to be the pharyngeal pouches.

\section{Discussion}

A novel nuclear factor of the Bowline/Ripply family protein was isolated in the mouse, African clawed frog, zebrafish, and amphioxus (Chan et al., 2007; Chan et al., 2006; Kawamura et al., 2005; Kondow et al., 2006; Li et al., 2006; Morimoto et al., 2007). Recently, we reported that Bowline, one of the Xenopus Bowline/ Ripply family proteins, functions as a negative regulator of Tbx6 

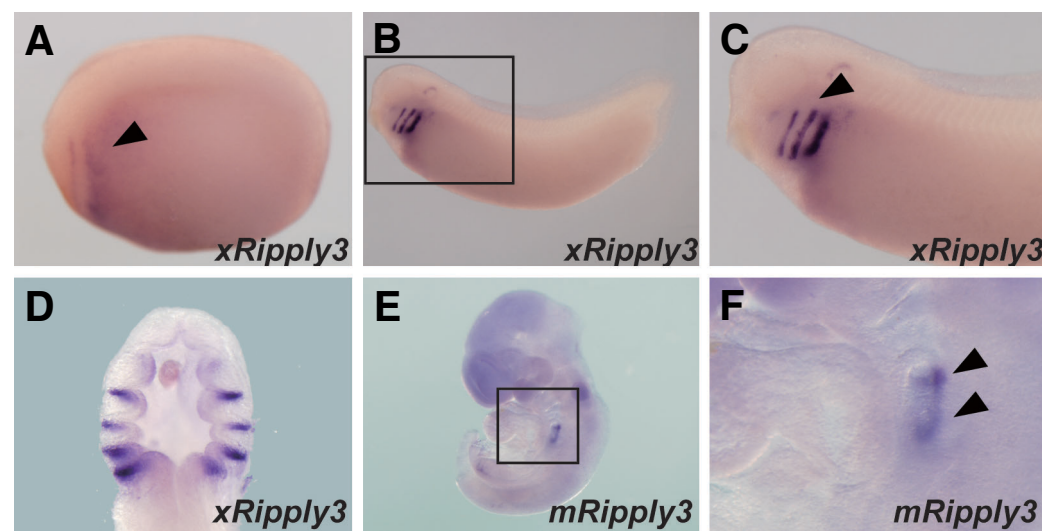

Fig. 6. Expression profile of Ripply3 during X. laevis and mouse development. (A-C) Whole-mount in situ hybridization for $x$ Ripply3. (A) At the late neurula stage, xRipply3 is expressed in the region near the heart mesoderm. (B) At the tailbud stage, $x$ Ripply3 expression is restricted to the pharyngeal region. Panel (C) is a magnified view of (B). Lateral views are shown with the anterior towards the left. The arrowheads in $(A)$ and $(C)$ indicate xRipply3 expression. (D) Tailbud-stage embryos stained with the xRipply3 probe were sliced frontally. (E,F) Whole-mount in situ hybridization for murine Ripply3. (E) Murine Ripply3 expression is observed in the pharyngeal region. Panel (F) is a magnified view of (E). The arrowheads in (F) indicate murine Ripply3 expression. proteins (Kondow et al., 2007). In zebrafish somitogenesis, Ripply1 also negatively regulates the transcriptional activity of the Tbx24 protein (Kawamura et al., 2008). However, whether the repressive activity for T-box proteins is a feature common to all Bowline/ Ripply family proteins has not been revealed. In the present work, we addressed this question. We investigated the molecular function of Ledgerline, another Xenopus Bowline/Ripply family protein, in somitogenesis. Similar to the knockdown of Bowline, knockdown of Ledgerline resulted in the anterior expansion of the expression regions of several somitogenesis-related genes. We found that Ledgerline had suppressive activity against the transcriptional activity of Tbx6. In addition, we isolated a novel Xenopus bowline/Ripply family gene, xRipply3, and investigated its molecular functions. Unlike the already known bowline/Ripply family genes, $x$ Ripply 3 is expressed in the pharyngeal region. Moreover, xRipply3 suppresses the transcriptional activity of Tbx1. Therefore, our findings demonstrate that Bowline/Ripply family proteins have the common feature of being negative regulators of T-box proteins (Fig. 8).

A previous study showed that ledgerline is expressed in the anterior PSM during Xenopus somitogenesis (Chan et al., 2006). However, the localization of ledgerline transcripts in the anterior PSM was not clearly defined. Our analysis of the region of ledgerline expression reveals that ledgerline is expressed in both the newly formed somites and the SO, S-I, and S-II somitomeres. Bowline is expressed in the S-I, S-II, and S-III somitomeres. Thus, there is overlapping expression of ledgerline and bowline in the SI and S-II somitomeres. In addition, we reveal the transcription factors involved in the regulation of ledgerline expression. Tbx6, mespb, and E47 regulate bowline expression during Xenopus somitogenesis (Hitachi et al., 2008b). Overexpression of Tbx6, mespb, and E47induced ectopic ledgerline expression, as well as bowline expression, in early-stage Xenopus embryos. Knockdown of Tbx6 by the Xtbx6 exint-MO abolished the expression of
Fig. 7. xRipply3 suppresses the transcriptional activity of Tbx1. (A) Schematic diagram of pGL4-Tbox, which contains tandem T-box binding sites. (B,C) Luciferase assays for the pGL4-Tbox construct. (B) Tbx 1 dose-dependently increases the luciferase activity of pGL4-Tbox. COS7 cells were transfected with the pGL4-Tbox (100 ng) and the Tbx1 expression vector (50-200 ng). (C) xRipply3 represses the transcriptional activity of Tbx 1 in the pGL4-Tbox construct. COS7 cells were transfected with pGL4-Tbox (100 ng) and a combination of the indicated expression vectors, Tbx1 (50 ng) and xRipply3 (25-100 ng). Error bars represent the SEM of three independent experiments. (D) Interaction between the xRipply3 and Tbx1 proteins in Xenopus embryos. Protein extracts of Xenopus embryos co-injected with myc-Tbx 1 mRNA and HA-xRipply3 mRNA (500 pg each) were subjected to co-immunoprecipitation with the anti-myc antibody. (E) Interaction between the xRipply3 and Grg4 proteins in Xenopus embryos. Protein extracts of Xenopus embryos co-injected with myc-Grg4 mRNA and HA-xRipply3 mRNA (500 pg each) were subjected to co-immunoprecipitation with the anti-myc antibody. The asterisks indicate non-specific bands. (F-H) Frontal sections of Xenopus embryos were stained for xRipply3 (F), Fgf8 (G), and Tbx1 (H) transcripts. The regions of $x$ Ripply3 and Fgf8 expression differ from those of $\mathrm{Tbx} 1$.
A

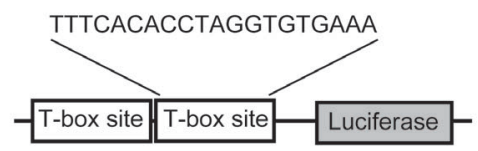

D

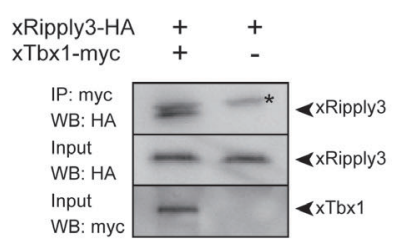

E
B
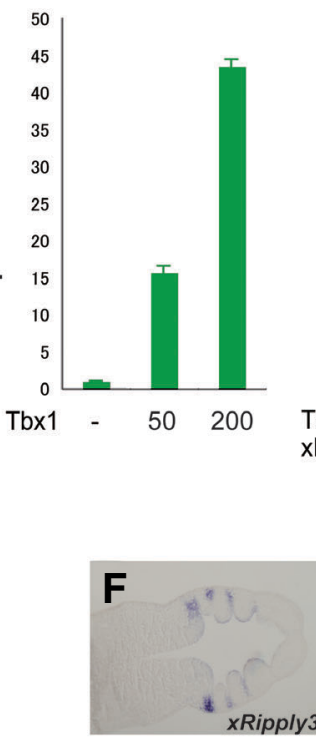

H
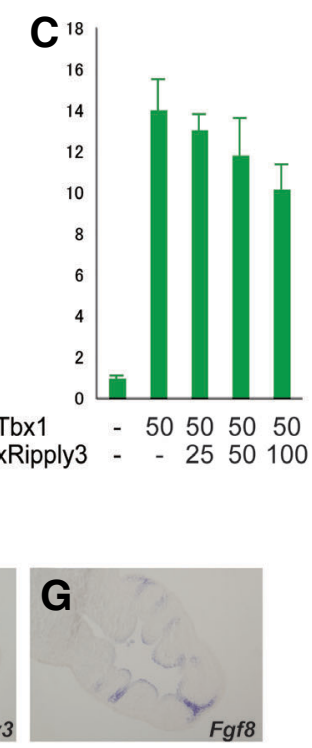

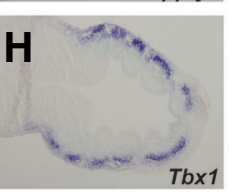


both ledgerline and bowline during Xenopus somitogenesis. Thus, it appears that Tbx6, mespb, and E47 are involved in the regulation of both ledgerline and bowline. Unexpectedly, although the decrease in bowline expression by $\mathrm{Xtbx6}$ exint-MO was rescued by co-injection of Xtbx6 exint-MO with Tbx6 mRNA, the decrease in ledgerline expression was scarcely rescued by coinjection of Tbx6 mRNA. Taken together, our data suggest that the mechanism responsible for ledgerline regulation is not identical to that for bowline regulation, although Tbx6 works as common regulatory factor for bowline and ledgerline expression during Xenopus somitogenesis.

The molecular function of Ledgerline was found to be similar to that of Bowline. Ledgerline interacted with the Tbx6 and Groucho/ TLE proteins, and suppressed the transcriptional activity of the Tbx6 protein. These findings suggest functional redundancy of Bowline and Ledgerline with respect to the negative regulation of Tbx6 during somitogenesis. This is supported by the finding that inhibition of both Ripply1 and Ripply2 induces dramatic upregulation of Mesp genes in zebrafish (Moreno et al., 2008). Furthermore, we found that treatment with the HDAC inhibitor TSA resulted in the anterior expansion of mespb expression region during Xenopus somitogenesis, as seen in embryos with knock-downs of Bowline and Ledgerline. Therefore, HDAC appears to be required for the suppressive activities of Bowline/ Ripply proteins in vivo. Taken together, Bowline and Ledgerline may redundantly suppress the transcriptional activity of Tbx6, using HDAC to repress completely the transcription of somitogenesis-related-genes in the anterior PSM during Xenopus somitogenesis.

In the present study, we isolated a third Xenopus bowline/ Ripply family gene and designated it as $x$ Ripply3. One remarkable property of $x$ Ripply 3 is its expression profile. The expression patterns of the known bowline/Ripply family genes are restricted to the anterior PSM, whereas that of $x$ Ripply 3 is observed in the pharyngeal region. Thus, $x$ Ripply 3 is assumed to be a novel bowline/Ripply family gene. xRipply3 interacted with Tbx1 protein in Xenopus embryos, and suppressed the transcriptional activity of Tbx1 in cultured cells. Considering the findings that (1) the expression patterns of $x$ Ripply 3 and Tbx 1 were not identical in Xenopus embryos, and (2) Ledgerline and Ripply1 limited the Tbx6 and Tbx24 expression in the PSM, respectively (Kawamura et al., 2005), one possible function of xRipply3 in the pharyngeal apparatus is to limit the $T b x 1$ expression in the pharyngeal arches by repressing its expression in the pharyngeal pouches.

In summary, we describe the expression profiles of two Xenopus bowline/Ripply family genes, ledgerline and $x$ Ripply3, in the anterior PSM and pharyngeal region, and reveal that they suppress the transcriptional activities of the T-box proteins. In future studies, it will be important to investigate the molecular mechanism(s) underlying the physiologic roles of xRipply3 during pharyngeal development.

\section{Materials and Methods}

\section{Isolation of the Xenopus Ripply3 gene}

The $x$ Ripply 3 cDNA was PCR-amplified from Xenopus laevis cDNA using the Phusion High-Fidelity polymerase (Finnzyme), and subcloned into the pBluescript II SK vector to generate pBS-Ripply3. The following primer set was used: 5'-GCAAACTAGGAATAAACAAG-3' and 5'CAAAAACATACATATCTTTAATAAAT-3'. Rapid amplification of cDNA
A

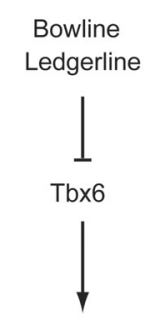

Somitogenesis
B

xRipply3

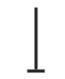

Tbx1?

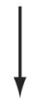

Pharyngeal development?

Fig. 8. Diagram illustrating the molecular functions of Bowline/ Ripply family proteins in Xenopus development. (A) Bowline and Ledgerline participate in somitogenesis as negative regulators of Tbx6 activity, since Bowline and Ledgerline suppress the transcriptional activity of Tbx6, which is required for the normal segmentation program of somites. (B) A third Xenopus Bowline/Ripply protein, xRipply3, has the potential to suppress the transcriptional activity of $T b x 1$ required for pharyngeal arch and pouch development, which suggests that xRipply3 functions as a negative regulator of Tbx 1 activity in pharyngeal pouch development.

ends (RACE) was performed using the FirstChoice RLM-RACE kit (Ambion). The coding region of $x$ Ripply 3 was PCR-amplified and inserted into the pCS2+ vector, to generate pCS2-xRipply3.

\section{Plasmid constructs}

The coding regions of the Xenopus Tbx 1 and mouse Ripply3 genes were PCR-amplified and subcloned into pBluescript SK-II, to create pBSTbx1 and pBS-mRipply3, respectively. The coding region of ledgerline was PCR-amplified and subcloned into the pCS2+ and HA-tagged pCS2+ vectors, to generate pCS2-Ledgerline and pCS2-HA-Ledgerline, respectively. The coding region of Xenopus Tbx1 was PCR-amplified and subcloned into the myc-tagged pCS2+ vector, to generate pCS2-mycTbx1. To produce the pGL4-Tbox construct, the Tbx1 binding site (5'TTTCACACCTAGGTGTGAAA-3'), as described previously (Ataliotis et al., 2005), was tandemly inserted into the pGL4.23 vector (Promega). The pCS2-Bowline, pCS2-Grg4, pCS2-Tbx6-VP16, pCS2-Xotch $\Delta E$, pCS2mespb (previously referred to as pCS2-Thy1), pCS2-E47, pCS2-mycTbx6, and pCS2-myc-Grg4 plasmids have been described previously (Hitachi et al., 2008b; Kondow et al., 2006; Kondow et al., 2007; Uchiyama et al., 2001). The pGL4.2Thy1 construct, which contains the 5'-flanking region of Xenopus mespb, has also been described previously (Kondow et al., 2007).

\section{Embryo manipulation, micro-injection and whole-mount in situ hy- bridization}

$X$. laevis embryos were obtained using a standard procedure (Abe et al., 2004). The staging of embryos was according to the scheme of Nieuwkoop and Faber (Nieuwkoop and Faber, 1956). In vitrotranscription of mRNA was carried out according to the procedure described previously (Nitta et al., 2007; Uchiyama et al., 2001). The following antisense morpholinos were obtained from Gene Tools: Control-MO, 5'CCTCTTACCTCAGTTACAATTTATA-3'; Ledgerline-MO, 5'AACTCCGCTGTTGATTCGGCTCCAT-3' (Chan et al., 2006); and Xtbx6 exint-MO, 5'-TGCCCCAGTCACATACCTGAGTATC-3' (Tazumi et al., 2008). Rescue experiments were performed by injecting embryos with Xtbx6 exint-MO (50 ng), together with Xenopus Tbx6 mRNA (2 or $10 \mathrm{pg}$ ) and $\beta$-galmRNA (200 pg). To inhibit endogenous HDAC activity, Xenopus embryos at stage 15 were treated with $500 \mathrm{nM}$ trichostatin A (Wako Pure Chemicals) for $4 \mathrm{hrs}$ at $23^{\circ} \mathrm{C}$. Whole-mount in situ hybridization of Xenopus and mouse embryos was performed as described previously (Chan et al., 2007; Harland, 1991; Sive et al., 2000). In situ hybridization of sections was performed using the Discovery system (Ventana Medical Systems), as described previously (Hitachi et al., 2008c). The templates 
for the bowline, mespb, and Tbx6 probes have been described (Hitachi et al., 2008b). The pCS2-Ledgerline, pBS-Tbx1, pBS-xRipply3, and pBSmRipply3 constructs were used as templates for the probes. The template for Fgf8 was kindly gifted by Dr. K. Tamura (Tohoku University). Galactosidase staining was carried out as described previously (Yabe et al., 2006), except that the chromogenic reaction was performed with Magenta-Gal as the substrate.

\section{Reverse transcriptase-polymerase chain reaction (RT-PCR)}

The procedures used for RT-PCR were as previously described (Suzawa et al., 2007). Xenopus embryos were injected with $500 \mathrm{pg}$ of Tbx6, mespb, and E47 mRNA. Total RNA was extracted from Xenopus stage-10 embryos using Isogen (Wako). The following primers were used: for bowline, forward 5'-CAAGTGGTTTGCCAAGTCCT-3' and reverse, 5'-AGCCAAGGTCTCCAGAACAA-3'; for ledgerline, forward 5'CAATGTGGCAGTGTGGAGAC-3' and reverse, 5'TGGAGGTTTCCCTTTGTCAT-3'; and for Ornithine decarboxylase (ODC), forward 5'-GTCAATGATGGAGTGTATGGATC-3', and reverse, 5'TCCATTCCGCTCTCCTGAGCAC-3'.

\section{Cell culturing, luciferase assays, subcellular localization and co- immunoprecipitation assay}

Culturing of COS7 cells and the luciferase assay were performed as previously described (Hitachi et al., 2008a). The pCS2-Tbx6-VP16, pCS2-Ledgerline, pCS2-Grg4, pCS2-Bowline, pCS2-Tbx6, pCS2xRipply3, and pCS2-myc-Tbx1 constructs were used as expression vectors. To normalize for transfection efficiency, $5 \mathrm{ng}$ of the pGL-4.74 vector (Promega), which expresses the Renilla luciferase, was cotransfected in all the experiments. The data from each experiment were compared with the basal activity of the pGL4-Tbox or pGL4.2Thy1 construct, and are presented as n-fold increases over the respective activities of these plasmids. The experiments were performed at least twice in triplicate for each assay, and representative data are shown.

To examine the subcellular localizations of the xRipply3 proteins, COS7 cells were transfected with $200 \mathrm{ng}$ of pCS2-HA-xRipply3, and immunocytochemistry was performed as described previously (Danno et al., 2008) with an anti-HA antibody (Y-11; Santa Cruz Biotechnology).

Xenopus embryos were microinjected with a mixture of myc-Tbx6 mRNA and HA-ledgerline mRNA (500 pg each), myc-Grg4 mRNA and HA-ledgerline mRNA (500 pg each), myc-Tbx1 mRNA and HA-xRipply3 mRNA (500 pg each) or myc-Grg4 mRNA and HA-xRipply3 mRNA (500 pg each), and immunoprecipitation was performed with an anti-myc antibody (9E10; Santa Cruz Biotechnology), as described previously (Kondow et al., 2007)

\section{Acknowledgments}

We thank Dr. K. Tamura for the generous gift of the plasmid. We are grateful to Dr. K. Suzawa for drawing the schematic diagrams. This work was supported in part by a Grant-in-Aid for Scientific Research from the Ministry of Health, Labour and Welfare of Japan and by Wako Pure Chemical Industries, Ltd., Japan. H.D. was also supported by the Japan Society for the Promotion of Science for Young Scientists.

\section{References}

ABE, T., FURUE, M., MYOISHI, Y., OKAMOTO, T., KONDOW, A. and ASASHIMA, M. (2004). Activin-like signaling activates Notch signaling during mesodermal induction. Int J Dev Biol 48: 327-332.

ATALIOTIS, P., IVINS, S., MOHUN, T.J. and SCAMBLER, P.J. (2005). XTbx1 is a transcriptional activator involved in head and pharyngeal arch development in Xenopus laevis. Dev Dyn 232: 979-991.

BALDINI, A. (2005). Dissecting contiguous gene defects: TBX1. Curr Opin Genet Dev 15: 279-284.

BECKERS, J., SCHLAUTMANN, N. and GOSSLER, A. (2000). The mouse rib- vertebrae mutation disrupts anterior-posterior somite patterning and genetically interacts with a Delta1 null allele. Mech Dev 95: 35-46.

CHAN, T., KONDOW, A., HOSOYA, A., HITACHI, K., YUKITA, A., OKABAYASHI, K., NAKAMURA, H., OZAWA, H., KIYONARI, H., MICHIUE, T. et al. (2007). Ripply2 is essential for precise somite formation during mouse early development. FEBS Lett 581: 2691-2696.

CHAN, T., SATOW, R., KITAGAWA, H., KATO, S. and ASASHIMA, M. (2006). Ledgerline, a novel Xenopus laevis gene, regulates differentiation of presomitic mesoderm during somitogenesis. Zoolog Sci 23: 689-697.

CHAPMAN, D.L. and PAPAIOANNOU, V.E. (1998). Three neural tubes in mouse embryos with mutations in the T-box gene Tbx6. Nature 391: 695-697.

DANNO, H., MICHIUE, T., HITACHI, K., YUKITA, A., ISHIURA, S. and ASASHIMA, M. (2008). Molecular links among the causative genes for ocular malformation: Otx2 and Sox2 coregulate Rax expression. Proc Natl Acad Sci USA 105: 54085413.

HARLAND, R.M. (1991). In situ hybridization: an improved whole-mount method for Xenopus embryos. Methods Cell Biol 36: 685-695.

HITACHI, K., DANNO, H., KONDOW, A., OHNUMA, K., UCHIYAMA, H., ISHIURA, S., KURISAKI, A. and ASASHIMA, M. (2008a). Physical interaction between Tbx6 and mespb is indispensable for the activation of bowline expression during Xenopus somitogenesis. Biochem Biophys Res Commun 372: 607-612.

HITACHI, K., KONDOW, A., DANNO, H., INUI, M., UCHIYAMA, H. and ASASHIMA, M. (2008b). Tbx6, Thylacine1, and E47 synergistically activate bowline expression in Xenopus somitogenesis. Dev Biol 313: 816-828.

HITACHI, K., KONDOW, A., DANNO, H., NISHIMURA, Y., OKABAYASHI, K. and ASASHIMA, M. (2008c). Molecular analyses of Xenopus Mesp-related genes. Integrative Zoology in press.

KAWAMURA, A., KOSHIDA, S., HIJIKATA, H., OHBAYASHI, A., KONDOH, H. and TAKADA, S. (2005). Groucho-associated transcriptional repressor ripply1 is required for proper transition from the presomitic mesoderm to somites. Dev Cell 9: 735-744.

KAWAMURA, A., KOSHIDA, S. and TAKADA, S. (2008). Activator-to-repressor conversion of T-box transcription factors by the Ripply family of Groucho/TLEassociated mediators. Mol Cell Biol 28: 3236-3244.

KONDOW, A., HITACHI, K., IKEGAME, T. and ASASHIMA, M. (2006). Bowline, a novel protein localized to the presomitic mesoderm, interacts with Groucho/TLE in Xenopus. Int J Dev Biol 50: 473-479.

KONDOW, A., HITACHI, K., OKABAYASHI, K., HAYASHI, N. and ASASHIMA, M. (2007). Bowline mediates association of the transcriptional corepressor XGrg4 with Tbx6 during somitogenesis in Xenopus. Biochem Biophys Res Commun 359: 959-964.

KOZAK, M. (1987). At least six nucleotides preceding the AUG initiator codon enhance translation in mammalian cells. J Mol Biol 196: 947-950.

LI, X., ZHANG, W., CHEN, D., LIN, Y., HUANG, X., SHI, D. and ZHANG, H. (2006). Expression of a novel somite-formation-related gene, AmphiSom, during amphioxus development. Dev Genes Evol 216: 52-55.

MORENO, T.A., JAPPELLI, R., BELMONTE, J.C. and KINTNER, C. (2008). Retinoic acid regulation of the Mesp-Ripply feedback loop during vertebrate segmental patterning. Dev Biol 315: 317-330.

MORIMOTO, M., SASAKI, N., OGINUMA, M., KISO, M., IGARASHI, K., AIZAKI, K., KANNO, J. and SAGA, Y. (2007). The negative regulation of Mesp2 by mouse Ripply2 is required to establish the rostro-caudal patterning within a somite. Development 134: 1561-1569.

NACKE, S., SCHAFER, R., HABRE DE ANGELIS, M. and MUNDLOS, S. (2000). Mouse mutant «rib-vertebrae» (rv): a defect in somite polarity. Dev Dyn 219: 192-200.

NAICHE, L.A., HARRELSON, Z., KELLY, R.G. and PAPAIOANNOU, V.E. (2005). T-box genes in vertebrate development. Annu Rev Genet 39: 219-239.

NIEUWKOOP, P.D. and FABER, J. (1956). Normal Table of Xenopus laevis (Daudin). North-Holland, Amsterdam.

NITTA, K.R., TAKAHASHI, S., HARAMOTO, Y., FUKUDA, M., TANEGASHIMA, K., ONUMA, Y. and ASASHIMA, M. (2007). The N-terminus zinc finger domain of Xenopus SIP1 is important for neural induction, but not for suppression of Xbra expression. Int J Dev Biol 51: 321-325.

POURQUIE, O. and TAM, P.P. (2001). A nomenclature for prospective somites and 
phases of cyclic gene expression in the presomitic mesoderm. Dev Cell 1: 619620.

SHOWELL, C., CHRISTINE, K.S., MANDEL, E.M. and CONLON, F.L. (2006) Developmental expression patterns of Tbx1, Tbx2, Tbx5, and Tbx20 in Xenopus tropicalis. Dev Dyn 235: 1623-1630.

SIVE, H.L., GRAINGER, R.M. and HARLAND, R.M. (2000). Early Development of Xenopus laevis: A Laboratory Manual. Cold Spring Harbor Laboratory Press, New York.

SUZAWA, K., YUKITA, A., HAYATA, T., GOTO, T., DANNO, H., MICHIUE, T., CHO, K.W. and ASASHIMA, M. (2007). Xenopus glucose transporter 1 (xGLUT1) is required for gastrulation movement in Xenopus laevis. Int J Dev Biol 51: 183190.

TAZUMI, S., YABE, S., YOKOYAMA, J., AIHARA, Y. and UCHIYAMA, H. (2008). pMesogenin 1 and 2 function directly downstream of Xtbx6 in Xenopus somitogenesis and myogenesis. Dev Dyn 237: 3749-3761.

THEILER, K. and VARNUM, D.S. (1985). Development of rib-vertebrae: a new mutation in the house mouse with accessory caudal duplications. Anat Embryol
(Berl) 173: 111-116.

UCHIYAMA, $\mathrm{H}$., KOBAYASHI, $T$., YAMASHITA, A., OHNO, $\mathrm{S}$. and YABE, $\mathrm{S}$. (2001). Cloning and characterization of the T-box gene Tbx6 in Xenopus laevis. Dev Growth Differ 43: 657-669.

WATABE-RUDOLPH, M., SCHLAUTMANN, N., PAPAIOANNOU, V.E. and GOSSLER, A. (2002). The mouse rib-vertebrae mutation is a hypomorphic Tbx6 allele. Mech Dev 119: 251-256.

WHITE, P.H., FARKAS, D.R., MCFADDEN, E.E. and CHAPMAN, D.L. (2003) Defective somite patterning in mouse embryos with reduced levels of Tbx6. Development 130: 1681-1690.

YABE, S., TAZUMI, S., YOKOYAMA, J. and UCHIYAMA, H. (2006). Xtbx6r, a novel T-box gene expressed in the paraxial mesoderm, has anterior neural-inducing activity. Int J Dev Biol 50: 681-689.

ZOUPA, M., SEPPALA, M., MITSIADIS, T. and COBOURNE, M.T. (2006). Tbx1 is expressed at multiple sites of epithelial-mesenchymal interaction during early development of the facial complex. Int J Dev Biol 50: 504-510.

\section{Further Related Reading, published previously in the Int. J. Dev. Biol.}

See our Special Issue The Spemann-Mangold Organizer edited by Edward de Robertis and Juan Aréchaga at:

http://www.ijdb.ehu.es/web/contents.php?vol=45\&issue=1

See our recent Special Issue Fertilization, in honor of David L. Garbers and edited by Paul M. Wassarman and Victor D. Vacquier at:

http://www.ijdb.ehu.es/web/contents.php?vol=52\&issue=5-6

Portuguese contributions to the discovery and characterization of the embryonic molecular clock

Susana Pascoal and Isabel Palmeirim

Int. J. Dev. Biol. (2008) 52: doi: 10.1387/ijdb.072285sp

The road to the vertebral formula

Moisés Mallo, Tânia Vinagre and Marta Carapuço

Int. J. Dev. Biol. (2008) 52: doi: 10.1387/ijdb.072276mm

Bowline, a novel protein localized to the presomitic mesoderm, interacts with Groucho/ TLE in Xenopus

Akiko Kondow, Keisuke Hitachi, Tempei Ikegame and Makoto Asashima Int. J. Dev. Biol. (2006) 50: 473-479

Xtbx6r, a novel T-box gene expressed in the paraxial mesoderm, has anterior neuralinducing activity

Shigeharu Yabe, Shunsuke Tazumi, Jun Yokoyama and Hideho Uchiyama Int. J. Dev. Biol. (2006) 50: 681-689

Tbx1 is expressed at multiple sites of epithelial-mesenchymal interaction during early development of the facial complex

Maria Zoupa, Maisa Seppala, Thimios Mitsiadis and Martyn T. Cobourne

Int. J. Dev. Biol. (2006) 50: 504-510

dTcf antagonises Wingless signalling during the development and patterning of the wing in Drosophila.

N Lawrence, P Dearden, D Hartley, J Roose, H Clevers and A M Arias

Int. J. Dev. Biol. (2000) 44: 749-756

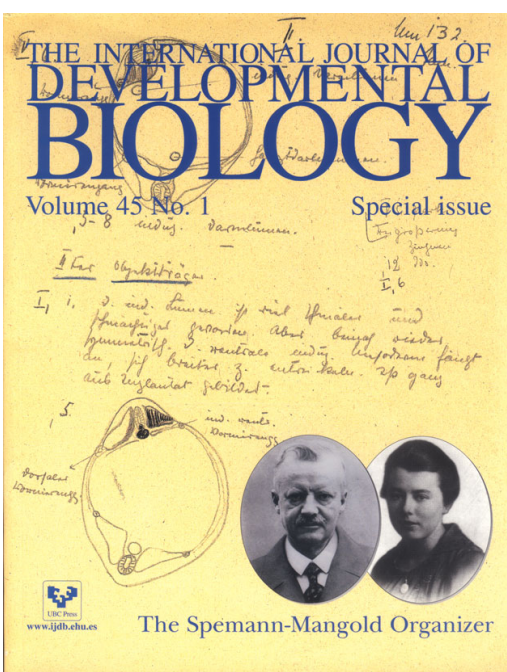

2006 ISI **Impact Factor $=3.577^{* *}$

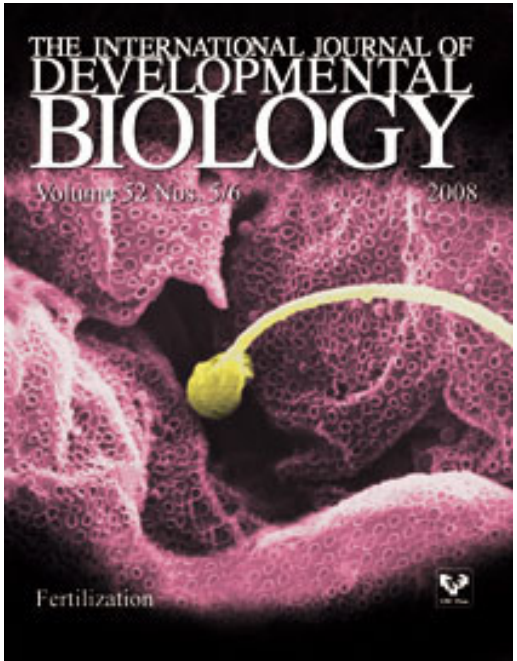

